\title{
1 QTL mapping: an innovative method for investigating the genetic 2 determinism of yeast-bacteria interactions in wine
}

4 Louise Bartle $^{1+}$, Emilien Peltier ${ }^{2,3,4}$, Joanna Sundstrom ${ }^{1,5}$, Krista Sumby ${ }^{1,5}$, James G Mitchell ${ }^{6}$, Vladimir 5 Jiranek ${ }^{1,5}$, Philippe Marullo ${ }^{2,3+}$

$6{ }^{1}$ The University of Adelaide, Department of Wine Science, Urrbrae, SA, 5064, Australia

$7 \quad{ }^{2}$ Université de Bordeaux, Unité de recherche CEnologie EA 4577, USC 1366 INRAe, Bordeaux INP;

8 ISVV, Villenave d'Ornon, France

$9 \quad{ }^{3}$ Biolaffort, Bordeaux, France

$10{ }^{4}$ Université de Strasbourg, CNRS, GMGM UMR 7156, Strasbourg, France

$11{ }^{5}$ Australian Research Council Training Centre for Innovative Wine Production, PMB1, Glen Osmond,

12 SA, 5064, Australia

$13{ }^{6}$ Flinders University, College of Science and Engineering, Adelaide, SA, Australia

$14 \quad{ }^{+}$Corresponding Authors: Louise Bartle louise.bartle@adelaide.edu.au, Philippe Marullo

15 philippe.marullo@u-bordeaux.fr

17 Keywords: Yeast-bacteria interactions, malolactic fermentation, QTL, wine, SSU1 


\section{Abstract}

20 The two most commonly used wine microorganisms, Saccharomyces cerevisiae yeast and

21 Oenococcus oeni bacteria, are responsible for completion of alcoholic and malolactic fermentation

22 (MLF), respectively. For successful co-inoculation, S. cerevisiae and $O$. oeni must be able to

23 complete fermentation, however, this relies on compatibility between yeast and bacterial strains. For

24 the first time, Quantitative Trait Loci (QTL) analysis was used to elucidate whether S. cerevisiae

25 genetic makeup can play a role in the ability of $O$. oeni to complete MLF. Assessment of 67 progeny

26 of an $S$. cerevisiae SBxGN cross, co-inoculated with a single $O$. oeni strain, SB3, revealed a major

27 QTL linked to MLF completion by $O$. oeni. This QTL encompassed a well-known translocation, XV-t-

$28 \mathrm{XVI}$, that results in increased SSU1 expression and is functionally linked with numerous phenotypes

29 including lag phase duration and sulfite export and production. A reciprocal hemizygosity assay was

30 performed to elucidate the effect of the gene SSU1 in the SBXGN background. Our results instead

31 revealed a strong effect of SSU1 haploinsufficiency on $O$. oenis ability to complete malolactic

32 fermentation during co-inoculation, and paves the way for the implementation of QTL mapping

33 projects for deciphering the genetic bases of microbial interactions.

\section{Key points:}

36 For the first time QTL analysis has been used to study yeast-bacteria interactions.

37 A QTL encompassing a translocation, $\mathrm{XV}$-t-XVI, was linked to MLF outcomes.

38 S. cerevisiae SSU1 haploinsufficiency positively impacted MLF by $O$. oeni. 


\section{Introduction}

Fermented beverages are the result of biotransformation of complex organo-chemical matrices by microbial communities of moulds, yeast, bacteria and bacteriophage (Bokulich and Bamforth 2013; Mounier et al. 2008; Renouf et al. 2007). Within these communities, the growth rate and metabolic activities of each microbial species depends on (i) the biochemical composition of the medium, (ii) the physicochemical conditions of the process (e.g. converting sugars to ethanol during juice fermentation), (iii) the physiological state of the microbes and (iv) cell-to-cell contact and metabolite interaction among microbial species.

Fermenting grape juice is a fast-changing environment that is especially interesting for studying how the two most common wine microbes, the yeast Saccharomyces cerevisiae and lactic acid bacterium Oenococcus oeni, coexist and interact. In an oenological context, microbial interactions may affect the final profile of volatile compounds (Chasseriaud et al. 2018, Renault et al. 2015, 2016), that subsequently can be detected as changes in wine sensorial complexity (Tempère et al. 2018). The importance of microbial interactions in wine is evident from the wide number of studies focusing on co-inoculated or sequential inoculation of $S$. cerevisiae and $O$. oeni, with the aim of decreasing overall fermentation time while maintaining or increasing wine quality (Abrahamse and Bartowsky 2012; Cañas et al. 2012, 2015; Knoll et al. 2012).

The mechanisms of yeast-lactic acid bacteria (LAB) interactions during juice fermentation have been reviewed recently (Bartle et al. 2019). Broadly, microbial interactions may include cell-cell contact (Nissen et al. 2003, 2004; Renault et al. 2013) or production of small metabolites (Renault et al. 2009; Sadoudi et al. 2012) and macromolecules (Comitini et al. 2005; Jarosz et al. 2014) that can inhibit and/or activate the growth and activity of interacting microbes. Understanding the molecular mechanisms of yeast-LAB interactions is a challenging task due to the confounding effects of the evolving complex growth environment and microbial metabolite production, but the benefits of such work include optimisation of yeast-LAB co-inoculation strategies for implementation in wineries.

S. cerevisiae and $O$. oeni interactions can affect their ability to complete alcoholic (AF) and malolactic fermentation (MLF), respectively (Bartle et al. 2019). Yeast may produce metabolic compounds that can inhibit LAB growth, including ethanol (Capucho and San Romão 1994; Gao and Fleet 1995; Guzzo et al. 2000), $\mathrm{SO}_{2}$ (Osborne and Edwards 2006), short and medium-chain fatty acids (Alexandre et al. 2004; Capucho and San Romão 1994), and antimicrobial peptides (Atanassova et al. 2003; Mendoza et al. 2010; Nehme et al. 2010). Yeast and LAB also have the potential to interact physically in the form of mixed species biofilms (Arroyo-López et al. 2012; Bartle et al. 2019; Furukawa et al. 2010) or through co-aggregation (Furukawa et al. 2011), though to date there have not been reports of this occurring between $S$. cerevisiae and $O$. oeni.

In addition to chemical and physical interactions, S. cerevisiae gene expression is affected by coinoculation with O. oeni (Rossouw et al. 2012). Differential gene expression in S. cerevisiae in response to co-inoculation with $O$. oeni included up-regulation of genes related to yeast stress response and possible competition for sulfur compounds compared to $S$. cerevisiae alone (Rossouw 
et al. 2012). Several studies have also reported strain-specific compatibility between yeast and LAB during co-inoculation (Abrahamse and Bartowsky 2012; Antalick et al. 2013; Arnink and Henick-Kling 2005; Comitini and Ciani 2007; Rossouw et al. 2012; Tristezza et al. 2016). Considering the strain specificity of compatibility outcomes, the intraspecific genetic variability of interacting species requires further investigation and analysis. To our knowledge, the identification of genetic variations to explain "strain compatibility" is a novel approach.

For $S$. cerevisiae, the genetic determinism of any complex trait can be investigated by mapping quantitative trait loci (QTLs) in a segregating progeny (Liti and Louis 2012). In the context of wine, this strategy has been used for elucidating the genetic basis of many traits of industrial interest (Peltier et al. 2019) including acetic acid production (Salinas et al. 2012), rate of nitrogen uptake (Brice et al. 2014; Jara et al. 2014), resistance to stuck fermentation (Marullo et al. 2019), resistance to low pH (Martí-Raga et al. 2017), and the production of aroma compounds (Eder et al. 2018; Huang et al. 2014; Roncoroni et al. 2011; Steyer et al. 2012). To date, QTL mapping has been performed for single pure cultures focusing on traits related to yeast fitness or effect on wine quality. However, this strategy may be applied to any trait resulting in measurable phenotypic variability. In the present work, we applied QTL mapping to delineate how S. cerevisiae genetic variability may affect the success of MLF in co-inoculated fermentations with a commercial strain of $O$. oeni.

\section{Materials and methods}

\section{Media}

Shiraz juice: Shiraz grapes (2017 vintage, Coombe vineyard, The University of Adelaide, Waite Campus, Urrbrae, South Australia) were harvested, de-stemmed, crushed and left to macerate at 0 ${ }^{\circ} \mathrm{C}$ for 7 days to enable polyphenolic extraction. Shiraz must be pressed and the juice stored at $-20^{\circ} \mathrm{C}$ until required. $\mathrm{No} \mathrm{SO}_{2}$ or antibacterial agents were added to the juice during pressing. Prior to experimentation Shiraz juice was filtered $(0.45 \mu \mathrm{m}$, catalogue \# FHT45, Air-Met Scientific, Victoria, Australia) to remove grape matter and solids. Initial measurements of total sugar were estimated by refractometry and sugar reduced to $250 \mathrm{~g} \mathrm{~L}^{-1}$ by addition of water. L-malic acid was increased to $2.5 \mathrm{~g}$ $\mathrm{L}^{-1}$ by addition of pure $\mathrm{L}-\mathrm{malic}$ acid and $\mathrm{pH}$ was decreased to 3.5 by addition of tartaric acid, followed by addition of $100 \mathrm{mg} \mathrm{L}^{-1}$ diammonium phosphate. Finally, the juice was filter sterilised $(0.2 \mu \mathrm{m})$.

Liquid de Man, Rogosa and Sharpe medium (MRS; catalogue \# AM103, Amyl Media, Victoria, Australia), supplemented with $20 \%$ apple juice (MRSAJ) was used for growing bacteria prior to inoculation. MRS was autoclaved and sterile apple juice $(0.2 \mu \mathrm{m}$ filtered) added post sterilisation and before use. MRSAJ supplemented with agar $(2 \%)$ and cycloheximide $(0.5 \%)$ following sterilisation of the medium, was used for enumeration of bacteria.

All yeast strains were initially streaked for single colonies on YPD agar (2\% glucose, $2 \%$ peptone, $1 \%$ yeast extract, $2 \%$ agar) and grown at $28{ }^{\circ} \mathrm{C}$, before growth of single isolates in YPD ( $2 \%$ glucose, $2 \%$ peptone, $1 \%$ yeast extract) at $28{ }^{\circ} \mathrm{C}$ overnight. If required, Geneticin (G418, $100 \mu \mathrm{g} \mathrm{mL}^{-1}$; catalogue \# 
115 G8168, Sigma-Aldrich, New South Wales, Australia) was added to YPD cultures to select for strains 116 carrying the KanMX deletion cassette.

\section{Strains and fermentations}

118

119

120

\section{Yeast strains}

Strains used in this work are listed in Table 1. QTL analysis was performed using the SBxGN yeast background. SBxGN is the F1-hybrid of SB and GN strains, two diploid, fully homozygous strains derived from the wine starters Actiflore $\AA$ BO213 and Zymaflore ${ }^{\circledR}$ VL1, respectively (Peltier et al. 2018b). The population used for QTL mapping consisted of 67 haploid progeny clones derived from the hybrid BN, an isogenic variant of SBxGN (Marullo et al. 2007a). These haploid meiotic progenies have been previously genotyped by whole genome sequencing (Martí-Raga et al. 2017). The effect of the gene SSU1 was assayed using the reciprocal hemizygosity assay by deleting each parental copy of SSU1 individually in the SBxGN F1-hybrid (Steinmetz et al. 2002a). The reciprocal hemizygous hybrids $\mathrm{S} \triangle \mathrm{G} 092$ and $\mathrm{G} \Delta \mathrm{S} 092$ were previously obtained as described by Zimmer and colleagues (2014).

\section{Yeast cell concentration and viability}

Yeast live cell concentrations were determined by flow cytometry. Yeast were diluted 100-times in sterile phosphate buffered saline (PBS), then stained with propidium iodide at a final concentration of $0.1 \mathrm{mg} \mathrm{mL}^{-1}$. Samples were analysed using a Guava ${ }^{\circledR}$ easyCyte ${ }^{\mathrm{TM}} 12 \mathrm{HT}$ flow cytometer (Luminex, Yokohama, Japan; previously Millipore, Darmstadt, Germany). Yeast concentrations were adjusted to inoculate sterile Shiraz juice at a final rate of $5 \times 10^{6}$ live cells $\mathrm{mL}^{-1}$.

\section{Bacteria}

Freeze-dried SB3 (Laffort@, South Australia, Australia) was grown anaerobically in MRSAJ for four days at $30{ }^{\circ} \mathrm{C}$ in $20 \% \mathrm{CO}_{2}$. Twenty-four hours prior to inoculation, bacteria were centrifuged $(2,236 \mathrm{x}$ g), the supernatant discarded and the cell pellet washed in sterile Shiraz juice before overnight incubation in fresh sterile Shiraz juice at $30{ }^{\circ} \mathrm{C}$. Bacteria were adjusted to an $\mathrm{OD}_{600}$ of 0.55 immediately prior to inoculation. For QTL library fermentations, $200 \mu \mathrm{L}$ of bacterial culture were added to each fermentation vessel manually through a silicone septum with a 21-gauge needle. For the hemizygote fermentations, $200 \mu \mathrm{L}$ of bacterial culture were transferred from a 96-well deep well plate to each fermentation vessel using an automated fermentation system (developed after performing the QTL experiment).

\section{Fermentations}

Fermentations were conducted using an automated fermentation system built on an EVO Freedom workdeck (Tecan, Männedorf, Switzerland; Fig. S1: Online resource 2). The system enabled 384 concurrent fermentations at a volume of up to $25 \mathrm{~mL}$. Full details of the system were described by Hranilovic et al. (2018) and can also be found on the University of Adelaide Biotechnology and 
150 Fermentation $\quad$ Facility website (https://sciences.adelaide.edu.au/agriculture-food-

151 wine/research/biotechnology-and-fermentation-facility).

152 Fermentation vessels were filled with $20 \mathrm{~mL}$ of sterile Shiraz juice and inoculated with yeast $\left(5 \times 10^{6}\right.$

153 live cells $\mathrm{mL}^{-1}$ ) followed by LAB inoculation 24 hours later. Sampling occurred daily, and fermentations

154 were homogenised by stirring prior to sampling. For the QTL mapping experiment, both parental

155 strains (SB and GN), the hybrid BN and the 67 haploid progenies were fermented as pure cultures (in

156 duplicate) or co-inoculated with SB3 (in triplicate). To test the effect of SSU1, hemizygous and wild

157 type F1- hybrids were assessed in triplicate for both pure and co-inoculated fermentations with SB3.

\section{Fermentation monitoring}

\section{Glucose and fructose consumption}

Glucose and fructose concentrations were determined enzymatically using commercially available kits (catalogue \# K-FRUGL, Megazyme, Bray, Ireland) following methods modified by Walker et al. (2014). Glucose and fructose consumption were used as determinants for progress of alcoholic fermentations, which were deemed complete when total glucose plus fructose concentration was $<4$ $165 \mathrm{~g} \mathrm{~L}^{-1}$.

The amount of glucose/fructose consumed over time was modelled by local polynomial regression fitting with the R-loess function, setting the span parameter to 0.8 . Five kinetics parameters were extracted from the model, which are described in Table 2.

\section{L-malic acid concentration}

L-malic acid was measured using an enzymatic test kit (catalogue \# 4A165, Vintessential Laboratories, Victoria, Australia) with modifications so that a plate-reader/spectrophotometer (Infinite 200 PRO, Tecan, Männedorf, Switzerland) could be used to measure absorbance. Specifically, each well of a 96 well micro-titre plate was dosed with $70 \mu \mathrm{L}$ buffer $(0.1 \mathrm{M}$ gly-gly, $0.1 \mathrm{M} \mathrm{L-glutamate,} \mathrm{pH}$ 10), $14 \mu \mathrm{L}$ nicotinamide adenine dinucleotide $\left(40 \mathrm{mg} \mathrm{mL}^{-1}\right), 70 \mu \mathrm{L}$ distilled water, $0.7 \mu \mathrm{L}$ glutamate oxaloacetate transaminase $\left(800 \mathrm{U} \mathrm{mL}^{-1}\right)$ and $5 \mu \mathrm{L}$ of sample or one of the L-malic acid standards (ranging from $0-3.0 \mathrm{~g} \mathrm{~L}^{-1}$ ). The plate was incubated at $22{ }^{\circ} \mathrm{C}$ for 3 minutes and the first absorbance was read at $340 \mathrm{~nm} ; 7 \mu \mathrm{L}$ of the 1:10 diluted L-malate dehydrogenase $\left(12,000 \mathrm{U} \mathrm{mL}^{-1}\right)$ was added and mixed into each well; the plate was incubated at $22{ }^{\circ} \mathrm{C}$ for 15 minutes before the second absorbance was measured at $340 \mathrm{~nm}$. L-malic acid in each sample was calculated from standard curves prepared with known L-malic acid concentrations. L-malic acid degradation was used as the determinant for MLF progress. L-malic acid consumed over time was modelled by local polynomial regression fitting with the R-loess function setting the span parameter to 0.75 . MLF was deemed complete when L-malic acid concentration was $<0.1 \mathrm{~g} \mathrm{~L}^{-1}$ and designated tend-MLF (Table 2).

184 L-malic acid end point parameters were determined for yeast alone and yeast-SB3 co-inoculation 185 fermentations. These parameters were: percentage of L-malic acid consumed or produced by yeast 
186 alone in relation to the starting L-malic acid concentration of $2.5 \mathrm{~g} \mathrm{~L}^{-1}$ (Pct_malic_AF), and percentage of L-malic acid consumed by yeast and LAB in co-inoculated fermentations (Pct_malic_co).

To estimate the overall L-malic acid reduction by LAB when co-inoculated with yeast, the average concentration of L-malic acid for co-inoculated fermentations at the end of experimentation was subtracted from the average L-malic acid concentration for corresponding yeast-alone fermentations. This parameter was designated Malic_acid_LAB_consumed. The end of the experiment was defined as either reduction of L-malic acid to $<0.1 \mathrm{~g} \mathrm{~L}^{-1}$ or approximately 11 days after the first yeast-LAB pair completed MLF.

A summary of all parameters assessed in this study can be found in Table 2 .

\section{Statistical analysis}

All statistical analyses were performed using $R$ versions 3.4.4 or higher ( $R$ Core Team 2017). Kendall correlation coefficient test was performed using R/stats package v3.6.2 (R Core Team 2017). The QTL mapping analysis was performed with the R/qtl package (Broman et al. 2003) by using the Haley-Knott regression model that provides a fast approximation of standard interval mapping (Haley and Knott 1992). A threshold corresponding to a $5 \%$ and $10 \%$ false discovery rate (FDR) was computed by performing 1000 permutations in order to assess the significance of the LOD score for QTL peaks (Churchill and Doerge 1994). The overall procedure was described by Peltier et al. (2018b) for multiple environments mapping.

Linear modelling was performed to evaluate the effect of allele, yeast background and translocation on MLF and AF parameters using the following formula:

$y_{i j}=m+B_{i}+T_{j}+B_{i} T_{j}+\epsilon_{i j}$

Where $y_{i j}$ is the value for the background $i(i=1,2)$ with translocation $j(j=1,2), m$ is the overall mean, $B_{i}$ is the yeast background effect, $T_{j}$ is the translocation effect, $B_{i} T_{j}$ is the interaction effect between yeast background and translocation, $\epsilon_{i j}$ is the residual error. Tukey post-hoc test $(\alpha=0.05)$ was used to elucidate differences between ANOVA test groups.

\section{Results}

\section{Biometric assessment of MLF completion in the SBxGN progeny population}

215 To identify QTLs influencing the completion of MLF, L-malic acid consumption by $O$. oeni was 216 measured in co-inoculated Shiraz grape juice fermentations. Alone, S. cerevisiae strains from the BN 217 progeny were able to consume a fraction of L-malic acid (Fig. 1a). The concentration of residual L218 malic acid at the end of $A F$ in yeast-alone fermentations ranged from $1.41 \mathrm{~g} \mathrm{~L}^{-1}$ to $2.75 \mathrm{~g} \mathrm{~L}^{-1}$, which 
219 corresponded to between $44 \%$ consumption and 10\% production of L-malic acid in respect to the 220 starting concentration of $2.5 \mathrm{~g} \mathrm{~L}^{-1}$ (Fig. 1b; Table S1: Online resource 1).

221 In the present study, the focus was the impact of yeast genotype on LAB MLF efficiency. Therefore,

222 we measured L-malic acid consumption over time for fermentations co-inoculated with $S$. cerevisiae

223 strains and LAB SB3 (Fig. 1c). As expected, L-malic acid consumption was much higher for many of

224 the yeast-LAB co-inoculated fermentations. However, SB3 was only able to complete MLF in 39 of the

22571 co-inoculated fermentations (Fig. 1d). Since LAB were only able to complete MLF when co-

226 inoculated with some of the SBxGN progenies, this provided evidence of strong yeast-LAB

227 interactions.

228 Though there were differences in residual L-malic acid across fermentations with different yeast 229 strains, the ability of yeast to consume L-malic acid (as seen for yeast-alone fermentations, Fig. 1a)

230 did not seem to impact MLF completion time by SB3 in co-inoculations. Kendall rank correlation 231 coefficient revealed only a weak positive correlation $(0.21, p=0.009)$ between the amount of L-malic 232 acid consumed by yeast and SB3 MLF completion time. 
bioRxiv preprint doi: https://doi.org/10.1101/2021.01.21.427107; this version posted January 22, 2021. The copyright holder for this preprint (which was not certified by peer review) is the author/funder, who has granted bioRxiv a license to display the preprint in perpetuity. It is made available under aCC-BY-NC-ND 4.0 International license.
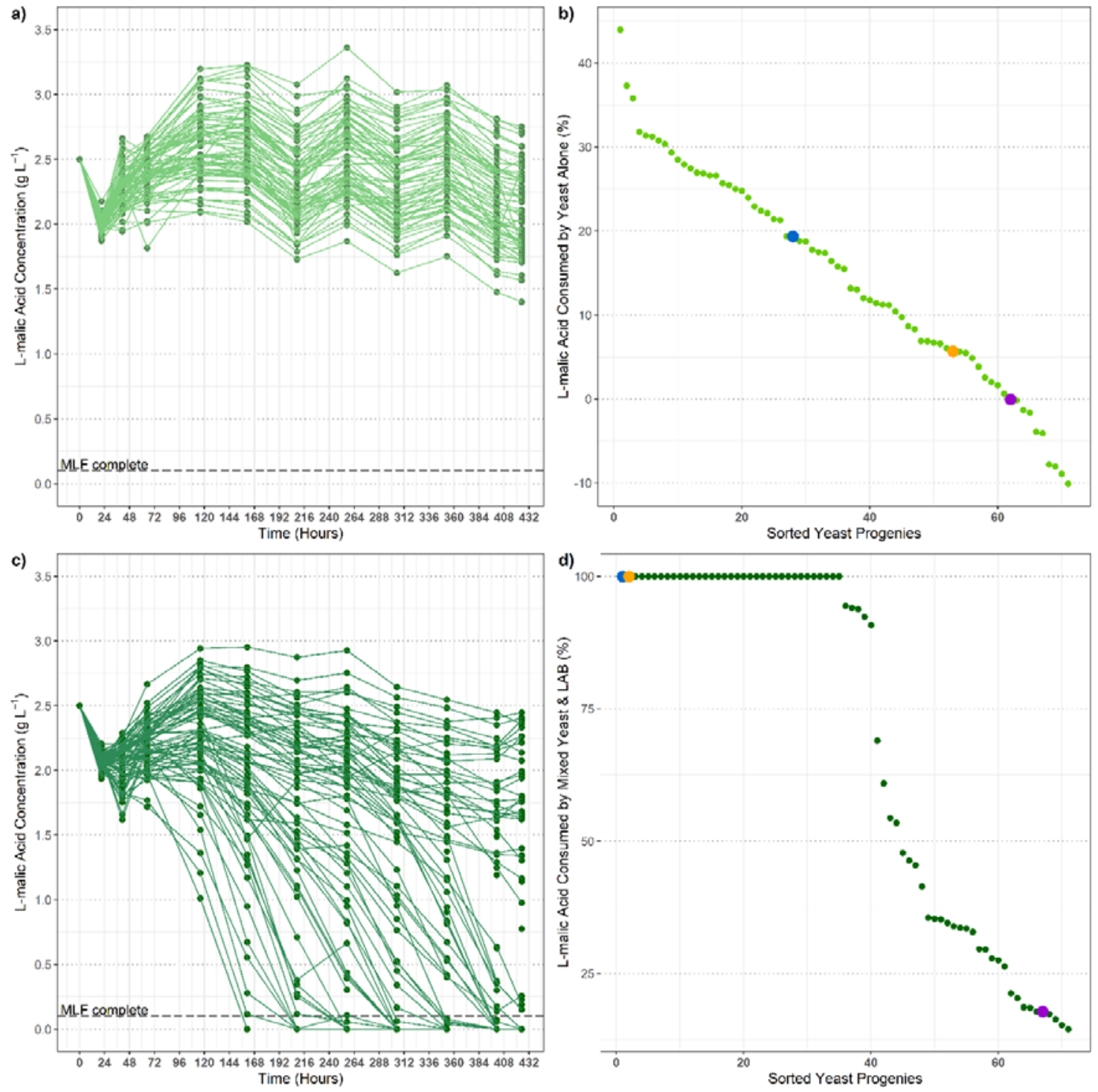

Fig. 1 a) L-malic acid concentration measured over the course of the experiment for yeast-alone fermentations for the population of $67 \mathrm{SBxGN}$ yeast progeny. Values are the mean of duplicates. b) All yeast-alone strains ranked by percentage of L-malic acid consumption (positive \%) or production (negative \%), measured at the end of the experiment in relation to the starting L-malic acid concentration of $2.5 \mathrm{~g} \mathrm{~L}^{-1}$. Percentages were calculated from the mean of duplicates. Colours indicate yeast parental strains: BN (orange), SB (blue) and GN (purple). All other yeast progeny are shown in green. c) MLF progress measured for yeast co-inoculated with SB3 LAB. Values are the mean of triplicates. The horizontal line at $0.1 \mathrm{~g} \mathrm{~L}^{-1}$ indicates when MLF was deemed complete. d) All yeast strains in co-inoculations with SB3 LAB were ranked by the percentage of L-malic acid consumed, measured at the end of the experiment. Percentages were calculated from the mean of triplicates. Colours are the same as panel $b$ 


\section{QTL mapping}

249 To determine the concentration of L-malic acid consumed only by LAB at the end of the experiment

250 (as defined in materials and methods), the average final L-malic acid concentration found in yeast-

251 LAB co-inoculations was subtracted from the corresponding L-malic acid concentration in yeast-alone

252 fermentations. This new parameter, the L-malic acid consumed by LAB (Malic_acid_LAB_consumed),

253 provides a proxy for SB3 MLF efficiency after co-inoculation with different yeast strains. This new

254 parameter has a nearly continuous distribution among the SBxGN progeny (Fig. 2a). Genetic regions

255 linked to the variation of this trait were tracked by applying a linkage analysis. Despite the small

256 number of progenies tested, two loci were linked to this phenotype at an FDR of $10 \%$ (Fig. $2 \mathrm{~b}$ ). One

257 QTL peak, located on S. cerevisiae chromosome XVI, achieved a LOD score of 7.58 which is highly

258 significant with respect to the threshold value of 4.58 that was estimated by 1000 permutations with

259 an FDR of $5 \%$. An additional peak, located on S. cerevisiae chromosome XV had a lower LOD score

260 of 4.02 . This LOD score reaches the threshold value of 4.00 which corresponds to an FDR of $10 \%$.

261 The best marker of this linkage analysis was located at genomic position XVI_374156 and was

262 therefore named XVI_374. Due to the density of markers surrounding XVI_374 (6 markers within 817

263 bp) and SSU1 spanning the genomic region of chromosome XVI: 373793-375169, there was high

264 confidence in the specificity of SSU1 being the target of the QTL peak. The inheritance of this marker

265 impacts the consumption of L-malic acid by the LAB SB3. Indeed, co-inoculated fermentations with

266 yeast progenies carrying the SB allele of XVI_374 consumed more L-malic acid than those performed

267 with yeast progenies carrying the GN allele (Fig. 2c). Interestingly, this phenotypic discrepancy is not

268 due to the ability of yeast to consume L-malic acid. Additionally, in yeast-alone fermentations, the

269 inheritance of XVI_374 from either SB or GN did not alter the percentage of L-malic acid consumed

270 by the yeast (Fig. 2d). In contrast, most of the strains containing the yeast SB allele for this QTL

271 allowed SB3 to complete MLF (Fig. 2c). Altogether, these data provide clear evidence that genetic

272 regions of the $S$. cerevisiae genome have a direct impact on the metabolic activity of LAB during co-

273 inoculation.

274 One peak detected did fall within the 10\% FDR (Fig. 2b) and therefore warrants discussion. This peak

275 was located on chromosome XV, at the marker XV_162503 which corresponds to the gene PHM7.

276 Although PHM7 is a gene of unknown function, in the SBXGN background a genetic linkage in this

277 region was predictable since the left arm of chromosome $X V$ is physically linked to chromosome XVI

278 in the strain GN. This well-documented translocation event was previously named XV-t-XVI (Zimmer

279 et al. 2014; Fig. 3) and segregates in a mendelian fashion in the SBxGN progeny. The XV-t-XVI

280 translocation has been demonstrated to impact several fermentation-related phenotypes including lag

281 phase duration, fermentation rate, and $\mathrm{SO}_{2}$ production. The molecular basis of such phenotypes is

282 due to modification of the promoter environment of the SSU1 gene (Fig. 3) that encodes Ssu1p, a

283 transmembrane sulfite efflux pump (Marullo et al. 2020; Peltier et al. 2018b; Zimmer et al. 2014).

284 These previous findings suggest that SSU1 would be a relevant candidate gene able to explain the

285 yeast-LAB interaction observed in our experiment. 

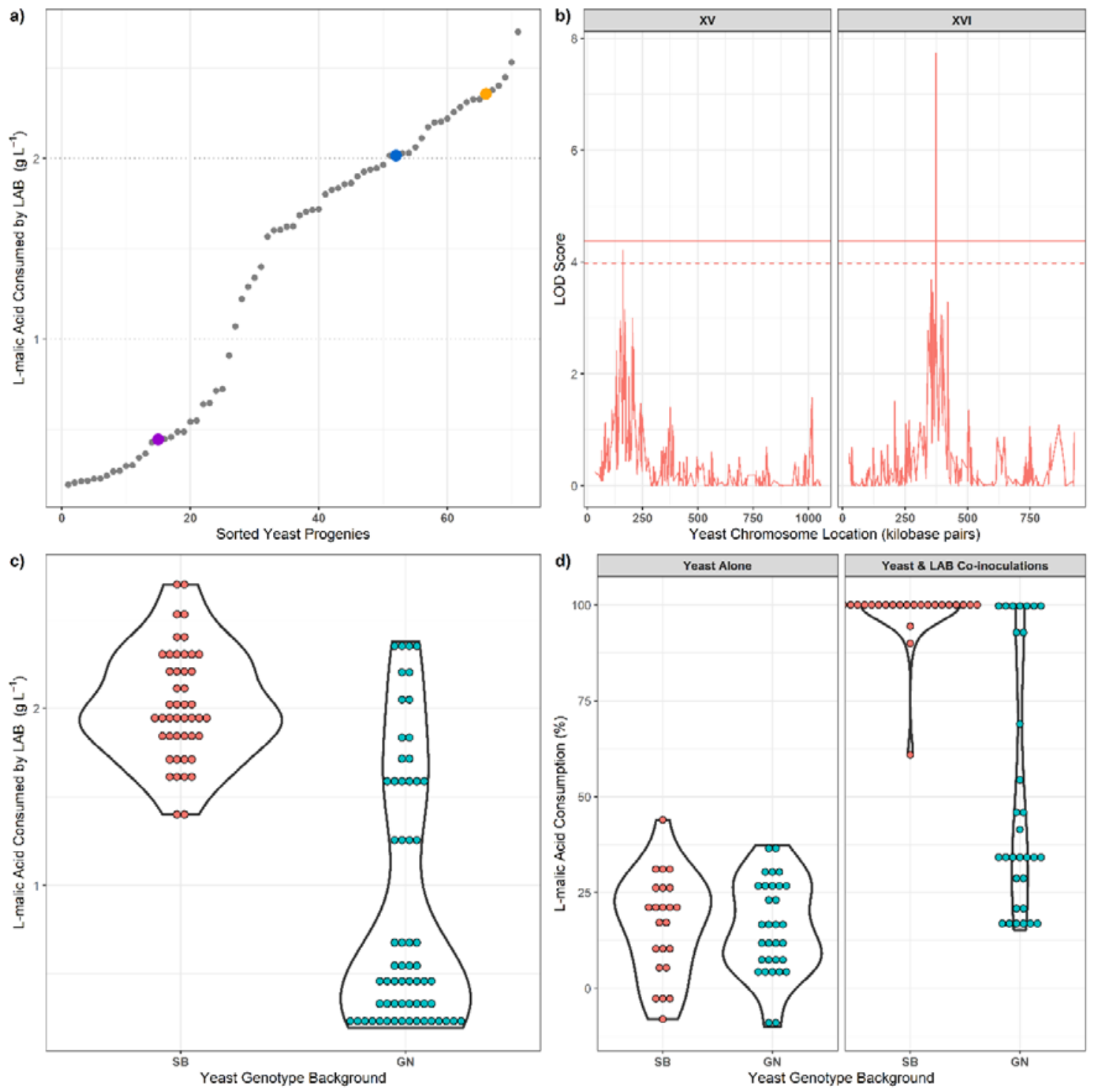

Fig. 2 a) Yeast ranked by the concentration of L-malic acid that was able to be consumed by SB3 during co-inoculation with each yeast strain. Values determined by subtracting the average residual Lmalic acid concentration of the yeast-alone fermentations from the average residual L-malic acid concentration in the corresponding yeast-LAB co-inoculation fermentations. Colours indicate yeast parental strains: BN (orange), SB (blue) and GN (purple). All other yeast progeny are shown in grey. b) Genomic location of QTL peaks for the parameter Malic_acid_LAB_consumed. Threshold values are estimated from 1000 permutations and 5\% FDR, indicated by the solid horizontal line. The dotted horizontal line indicates a LOD score threshold of 4 . Significant (peak above threshold) and potential (peaks near a LOD score of 4) QTLs were found on chromosomes XV (left) and XVI (right). c) Distribution of yeast progenies with respect to the concentration of L-malic acid consumed by SB3 in co-inoculations with each yeast strain. Progenies are grouped by yeast background (SB, left; GN, right). d) Distribution of yeast progenies based on percentage of L-malic acid consumed (measured at the end of experimentation) for yeast alone (left panel) or when co-inoculated with SB3 (right panel). 
303

Hybrid parental strains (diploid)

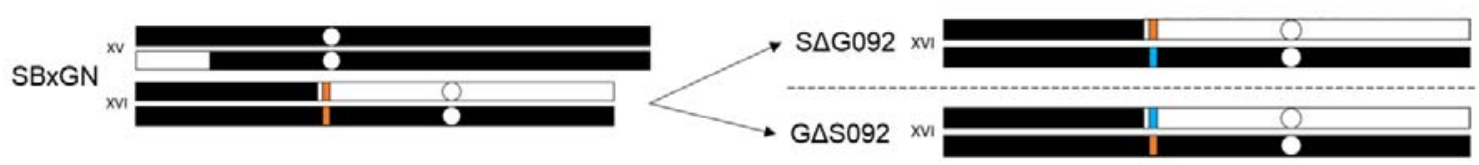

SSU1

KanMX casette

Fig. 3 Representation of the translocation located in SBxGN that results in increased SSU1 gene expression due to reduced proximity between SSU1 and promotor regions. SBXGN has an XV-t-XVI translocation that leads to a single copy of wild-type XV and XVI chromosomes (all black) and reciprocal XV and XVI translocated chromosomes (black and white). Hemizygous strains $S \triangle \mathrm{G} 092$ and G $\triangle S 092$ with a single functional SSU1 allele (orange) were generated to perform a reciprocal hemizygosity assay. Hemizygous strains were created by replacing a single copy of SSU1 with a KanMX cassette (blue)

\section{Functional study of a QTL closely related to SSU1}

To determine the possible influence of SSU1 on MLF outcome, we applied a reciprocal hemizygosity assay, enabling evaluation of the impact of the two parental alleles in an isogenic context, as proposed by Steinmetz et al. (2002b). To test this hypothesis, we used the hemizygous hybrids $\mathrm{S} \triangle \mathrm{G} 092$ and G $\Delta \mathrm{S} 092$ in which one copy of the SSU1 gene was replaced with the KanMx4 cassette (Zimmer et al. 2014). Such strains are isogenic to the F1-hybrid SBxGN but carry only one functional

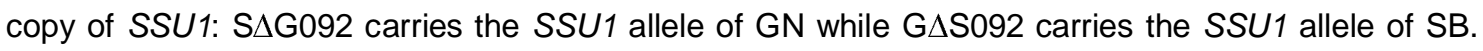
The two hemizygous hybrids were compared to the SBxGN hybrid carrying both functional SSU1 alleles.

Co-inoculated and yeast-alone fermentations were carried out in the same conditions applied for QTL mapping. In co-inoculated fermentation, all the malolactic fermentations were completed. However, the time taken for SB3 to reduce L-malic acid to $<0.1 \mathrm{~g} \mathrm{~L}^{-1}$ was significantly different depending on the yeast strain (Fig. 4a). Indeed, both hemizygous hybrids enabled shorter MLF completion time (by at least 48 hours) than the parental hybrid SBxGN, revealing a strong haploinsufficiency effect of the SSU1 deletion. Surprisingly, MLF completion was not significantly impacted by inheritance of either the SB or GN allele (Fig. 4b). This result led to the conclusion that the SSU1 gene was not the main cause of the SBxGN QTL on chromosome XVI that was based on L-malic acid consumption.

In addition to MLF, AF kinetics of isogenic hybrids co-inoculated with and without SB3 were also determined. The AF completion time (tend-AF) was significantly longer for $\mathrm{S} \triangle \mathrm{G} 092$ compared to SBxGN and G $\triangle S 092$ (Fig. 4c and d), but was unaffected by the presence of LAB. Additionally, in coinoculated fermentations, $\mathrm{S} \Delta \mathrm{G} 092$ (functional $\mathrm{GN}$ allele) had a significantly slower fermentation (Fig. 4c; ANOVA, Tukey post-hoc, $p<0.05$, Table S2: Online resource 2). Differences in AF kinetics between SSU1 hemizygous hybrids have been previously reported, where the GN allele correlated to reduced lag phase, increased cell viability (Zimmer et al. 2014) and longer fermentation completion 
336 time (Peltier et al. 2018b) in connection with the $\mathrm{SO}_{2}$ content of grape juice. For the present work, no sulfite was added to the grape juice, removing the influence of this antimicrobial agent. Therefore, the differences of fermentation kinetics observed for the $\mathrm{S} \triangle \mathrm{G} 092$ may be in part due to yeast-LAB interactions. This unexpected result suggests that $L A B$ co-inoculation with yeast may impact yeast fermentation fitness and allelic variations of SSU1 in yeast could modulate such interactions.
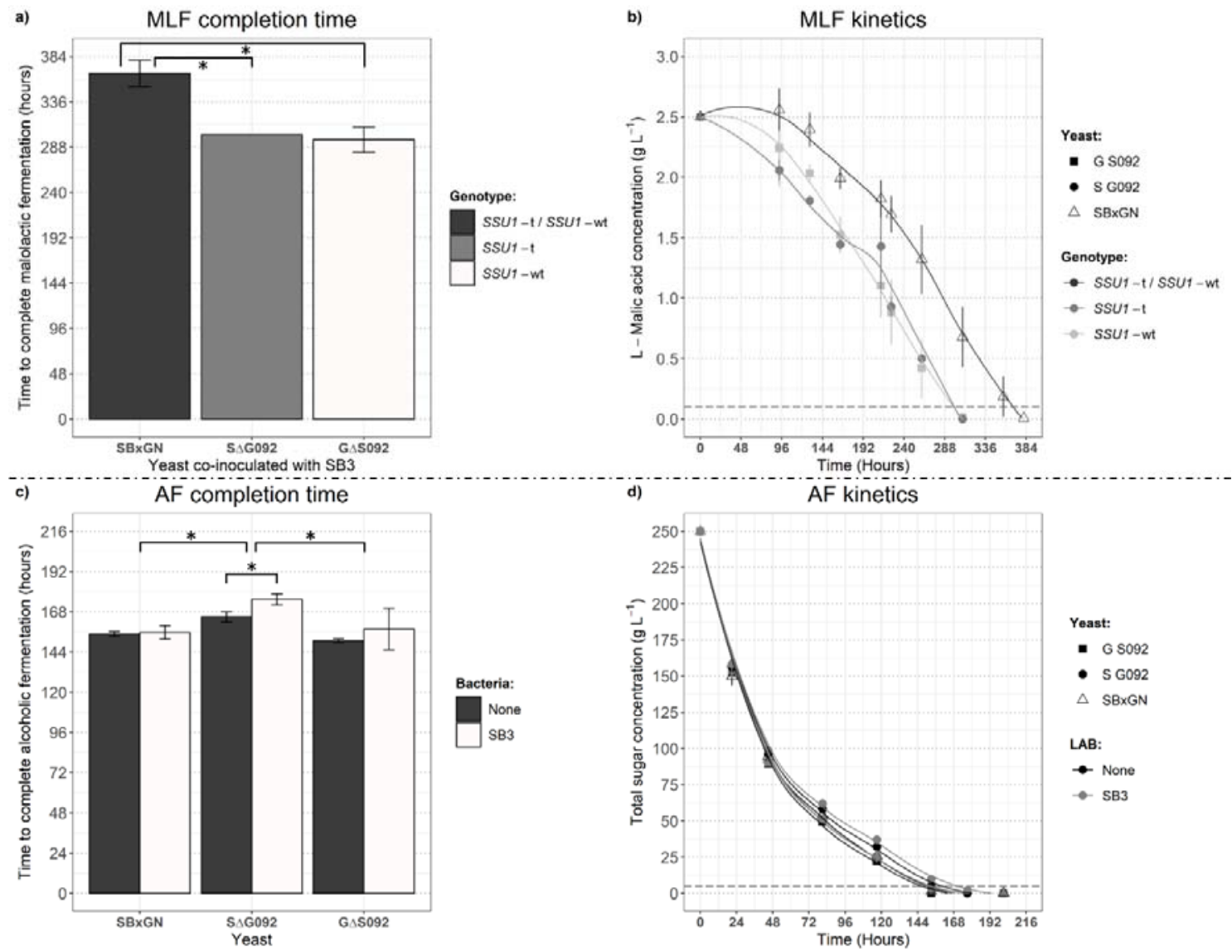

Fig. 4 a) Time taken for SB3 to complete malolactic fermentation during co-inoculation with SBxGN, $\mathrm{S} \triangle \mathrm{G} 092$ and $\mathrm{G} \triangle \mathrm{S} 092$. Bar colour indicates the yeast SSU1 genotype. Significant differences (ANOVA, Tukey post-hoc; $p<0.05$ ) between yeast are indicated by *. b) L-malic acid consumption over time by SB3 when co-inoculated with SBxGN (triangle), S $\triangle \mathrm{G} 092$ (circle) or G $\Delta$ S092 (square). Lines demonstrate fitting of local polynomial regression using the R-loess function, $\operatorname{span}=0.75$. $\mathbf{c}$ ) Time to complete alcoholic fermentation for yeast alone (filled bars) vs yeast co-inoculated with SB3 (colourless bars). Significant differences (ANOVA, Tukey post-hoc; $p<0.05$ ) are indicated by *. d) Total sugar consumption over time by SBxGN (triangle), S $\triangle$ G092 (circle) and G $\Delta$ S092 (square) alone (dark), or co-inoculated with SB3 (light). Lines demonstrate fitting of local polynomial regression using the R-loess function, span $=0.8$. Values are the mean of triplicates and error bars are the standard deviation 


\section{Discussion}

\section{microbial interactions}

362 MLF kinetics and production of volatile and non-volatile compounds (Arnink and Henick-Kling 2005;

363 Comitini and Ciani 2007; Mendoza et al. 2010; Nehme et al. 2008, 2010). Many combinations of yeast

364 and $L A B$, either sequentially or co-inoculated in juice or wine, have revealed that yeast-LAB

365 compatibility is strain specific (Comitini et al. 2005; Comitini and Ciani 2007; Muñoz et al. 2014).

366 Considering the differences reported for different yeast and LAB strains, and production of different

367 metabolites by yeast strains, there is no question of the influence that yeast genetic makeup has on

368 co-inoculation outcomes. In addition to studies on strain combination and metabolite production,

369 further work has revealed differential $S$. cerevisiae gene expression in response to co-inoculation with

370 O. oeni (Rossouw et al. 2012). Though insightful, none of these works have identified specific genetic

371 differences between yeast strains that may influence compatibility with $O$. oeni. Hence, the present

372 work has laid a foundation for understanding how $S$. cerevisiae genetic makeup can impact MLF

373 outcomes during co-inoculation with $O$. oeni. The application of a QTL mapping strategy was used to

374 find specific influences of yeast genetic makeup on yeast-LAB interactions.

375 In the past, QTL mapping has been used for investigating plant-pathogen interactions unveiling links

376 between plant genotype and pathogen resistance (Chen et al. 2010; Decroocq et al. 2005; Eun et al.

377 2016). In the current work, the same strategy was applied to the two main species involved in

378 winemaking: S. cerevisiae and $O$. oeni, to delineate the influence of yeast genetic background in

379 microbial interactions.

380 QTL mapping has been used numerous times for $S$. cerevisiae to determine the genotypic traits that 381 influence yeast AF completion (Marullo et al. 2019), acetic acid production (Marullo et al. 2007b; 382 Salinas et al. 2012), nitrogen uptake (Brice et al. 2014; Jara et al. 2014) and aroma compound 383 production (Eder et al. 2018; Huang et al. 2014; Roncoroni et al. 2011; Steyer et al. 2012) which are 384 important for fermentation progress and wine quality. However, to the best of our knowledge, QTL 385 mapping has not been used to study yeast-bacteria interactions in wine. To achieve this task, we 386 used the BN progeny clones (pop BN, Table 1) that have been previously used for investigating the 387 genetic determinism of fermentation traits (Martí-Raga et al. 2017; Zimmer et al. 2014). Each progeny 388 clone was co-inoculated (i.e. exposed) to LAB during fermentation and the percentage of L-malic acid 389 consumed was measured. For the S. cerevisiae strains alone, L-malic acid at the end of fermentation 390 ranged from $44 \%$ consumption to $10 \%$ production when compared to the starting concentration of 2.5 $391 \mathrm{~g} \mathrm{~L}^{-1}$ (Fig. 1b; Table S1: Online resource 1) and the ability of yeast to consume or produce this 392 amount of L-malic acid is in agreement with previous findings (Delcourt et al. 1995; Peltier et al. 393 2018a; Yéramian et al. 2007). The continuous distribution of L-malic acid consumption or production 
394 observed among the yeast progeny suggests that this trait is controlled by many genes. A study

395 detailing those genes is currently under preparation (Peltier, pers. comm.).

396 Since S. cerevisiae strains can consume some of the L-malic acid present in grape must, the specific

397 consumption of L-malic acid by LAB was determined by subtracting L-malic acid concentration in

398 yeast-alone fermentations from values in co-inoculations. This computed trait

399 (Malic_acid_LAB_consumed) was used to estimate the influence of yeast strain on $O$. oeni strain

400 SB3's ability to complete MLF. The ability of SB3 to complete MLF in co-inoculated conditions showed

401 a gaussian distribution, suggesting that several S. cerevisiae genes control this phenotype (Fig. 2a).

402 Although the number of progenies tested was low for achieving QTL mapping (67 clones), we

403 implemented a linkage analysis that revealed a major QTL (XVI_374) with a LOD score above an

404 FDR threshold of 5\%. The marker for this major QTL was located within SSU1, giving reason to

405 perform follow-up work with SSU1 hemizygote strains. Beside this major QTL, one other loci

406 (XV_162) reached a lower FDR threshold of approximately 10\%. The QTL XV_162 marker

407 corresponds to PHM7, a gene of unknown function. However, this marker was physically linked with

408 the major QTL XVI_374 due to the presence of the XV-t-XVI translocation that was previously

409 identified in this genetic background (Zimmer et al. 2014). Therefore, our strategy was useful for

410 narrowing down two unlinked genetic regions that impacted the success of MLF by SB3 in co-

411 inoculated fermentations.

\section{Putative role of SSU1 gene in yeast-LAB interactions}

414 Once identified by linkage analysis, QTLs can be dissected at the gene and single-nucleotide 415 polymorphism (SNP) level to further understand the underlying molecular genetic mechanism of 416 phenotypic traits (Peltier et al. 2019). However, this functional characterisation is a complex task that 417 cannot always be achieved. In the present study, there was no clear demonstration of the impact of 418 natural allelic variations linked to SB3 MLF completion in co-inoculated fermentations.

419 The QTLs identified in this study link two markers, XVI_374 and XV_162, to the phenotype 420 investigated. These two QTLs belonging to chromosomes $X V$ and $X V I$ must be considered as a single 421 locus since they are physically linked by a reciprocal translocation event, XV-t-XVI, in the parental 422 strain GN. This translocation is detected in numerous wine related strains (Marullo et al. 2020; Treu et 423 al. 2014; Zimmer et al. 2014) and can impact numerous yeast phenotypes including lag phase 424 duration, cell viability (Zimmer et al. 2014), growth rate in the presence of $\mathrm{SO}_{2}$ (Marullo et al. 2020) 425 and alcoholic fermentation kinetics (Peltier et al. 2018b). These phenotypes have been attributed to 426 the modification of the promoter sequence of the gene SSU1, that encodes Ssu1p, an intermembrane 427 transporter responsible for S. cerevisiae sulfite efflux (Park and Bakalinsky 2000). In GN, the 428 translocation results in decreased distance between the $A D H 1$ promoter region and SSU1, triggering 429 increased and constitutive SSU1 expression (Zimmer et al. 2014). Interestingly, two other gross 430 chromosomal rearrangements related to the SSU1 promoter have been described in the past (García431 Ríos et al. 2019; Pérez-Ortín et al. 2002) and were associated with increased SSU1 expression as 
432 well as increased sulfite resistance (García-Ríos et al. 2019; Marullo et al. 2020). These chromosomal 433 rearragements have facilitated adaptation of wine yeast, enabling increased $\mathrm{SO}_{2}$ efflux from the yeast 434 cell in oenological conditions, and has been reviewed recently (Divol et al. 2012; García-Ríos and 435 Guillamón 2019). In terms of co-inoculation, yeasts that efficiently export sulfite could negatively 436 impact $\mathrm{O}$. oeni growth and MLF progress, as $\mathrm{SO}_{2}$ can inhibit the internal ATPase of this lactic acid 437 bacterium (Carrete et al. 2002). This is supported by the linkage analysis since the GN allele had a 438 deleterious effect on MLF completion (Fig. 2d). We tested this hypothesis by reciprocal hemizygosity 439 assay, including fermentations with and without $L A B$ co-inoculation and determining the percentage of 440 L-malic acid consumed by LAB. Although MLF was completed in all the co-inoculated fermentations, 441 a strong haploinsufficiency effect was observed between the native hybrid SBxGN and the two 442 hemizygous hybrids (Fig. 4a). Thus, the lack of one copy of SSU1 within yeast can enable 443 considerably reduced duration of MLF by LAB, no matter which SSU1 allele is deleted (Fig. 4a and b). 444 This result suggests that the SSU1 gene may play a role in the phenotype investigated. However, the 445 comparison of hemizygous hybrids fails to confirm the inhibitor role of the SSU1 GN allele specifically, 446 compared to SB. This negative result may be due to a masking effect of SSU1 haploinsufficiency, 447 suggesting that the negative impact of the GN allele may require two functional SSU1 alleles to be 448 fully expressed.

449 Intriguingly, the AF kinetics of the hemizygous strain $S \triangle G 092$, which carries the SSU1 GN allele, was 450 slightly delayed compared to $\mathrm{G} \triangle \mathrm{S} 092$ and $\mathrm{SBxGN}$ (Fig. 4c and d). In addition, when $\mathrm{S} \triangle \mathrm{G} 092$ was co451 inoculated with $L A B$, this delay was longer (up to 20 hours) suggesting a possible inhibition of yeast $452 \mathrm{AF}$ by bacteria. This deleterious effect of the GN allele on fermentation kinetics has been previously 453 reported (Peltier et al. 2019) and was attributed to the increase of external sulfite in the fermented 454 medium, a direct effect of increased $\mathrm{SO}_{2}$ efflux. However, in our conditions, sulfite concentration was

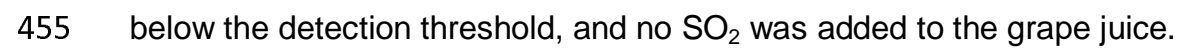

456 The inability to confirm the QTL using the reciprocal hemizygosity assay could be due to SSU1 not 457 being the main gene involved in MLF completion by LAB or AF activity. In fact, other genes 458 genetically linked to the GN allele of SSU1 could be involved in those phenotypes. Among them, $459 A D H 1$ may be an interesting candidate. $A D H 1$ encodes an alcohol dehydrogenase that is located on 460 chromosome XV, but is also physically associated with the SSU1 gene in the XV-t-XV translocation 461 genotype. In the first hours after yeast inoculation, expression of $A D H 1$ is not fully active. Ethanol 462 production is delayed and replaced by glycerol-pyruvic fermentation in order to cope with the 463 depletion of $\mathrm{NAD}^{+}$in the cytosol (Ribereau-Gayon et al. 2006). We hypothesise that the XV-t-XVI 464 translocation could also modify the expression of $A D H 1$, at least in the early stage of yeast culture. 465 Decreased $A D H 1$ expression in the early phase of AF could lower alcohol dehydrogenase activity, 466 increasing the accumulation of acetaldehyde. This phenomenon has been previously observed for 467 different wine starters including VL1, the parental strain of GN (Cheriati et al. 2010). The biological 468 implication of acetaldehyde utilisation by wine LAB in free or bound form is not yet fully understood, 469 apart from the liberation of free $\mathrm{SO}_{2}$ from the acetaldehyde- $\mathrm{SO}_{2}$ complex (Liu and Pilone 2000). High 470 levels (> $100 \mathrm{mg} \mathrm{L}^{-1}$ ) of acetaldehyde may inhibit growth of LAB (El-Gendy et al. 1983). Thus, the 
471 impact of the XVI_374 QTL observed in the SBxGN progeny might be due to other genetic 472 polymorphisms related to the XV-t-XVI translocation, such as the modification of the $A D H 1$ promoter 473 region. In future, additional experimental efforts will be required to further investigate these molecular 474 causes.

475 In conclusion, for the first time, yeast genetic background was assessed for its role in yeast-LAB 476 compatibility during fermentation. The impact of SSU1 haploinsufficiency on LAB ability to complete 477 MLF was clear, but further work is needed to understand the role of the XV-t-XVI translocation on 478 MLF outcomes. The inclusion of more progeny and use of a different genetic background may help 479 identify other genes that result in phenotypic differences in yeast-LAB co-inoculations. Further work 480 may also reveal the underlying cause of the major QTL identified in this study, which was not able to 481 be confirmed by the SSU1 hemizygote strains. However, the influence of SSU1 in this work does add 482 to the understanding of the pleiotropic role of SSU1, since it has been reported to impact yeast AF, 483 growth and $\mathrm{SO}_{2}$ production, and now also has the potential to impact co-inoculation outcomes with 484 LAB. This work begins to unravel the complexity of $S$. cerevisiae genetic differences that can lead to a 485 phenotype that impacts 0 . oeni during co-inoculation. Understanding the delicate interplay between 486 genotype and phenotype can create opportunities for wine yeast manufacturers to develop yeast that 487 work effectively with $L A B$, without negatively impacting yeast AF performance. 


\section{$490 \quad$ Funding}

491 This work was supported by Australia's grape growers and winemakers through their investment

492 body, Wine Australia, with matching funds from the Australian Government. LB was supported by joint

493 scholarships from The University of Adelaide and Wine Australia (AGW Ph 1510). JS was supported

494 by Wine Australia project funding (UA1707). JS, KS and VJ are supported by The Australian

495 Research Council Training Centre for Innovative Wine Production (www.ARCwinecentre.org.au;

496 project number IC170100008), which is funded by the Australian Government with additional support

497 from Wine Australia and industry partners. The University of Adelaide is a member of the Wine

498 Innovation Cluster in Adelaide (http://www.thewaite.org/waite-partners/wine-innovation-cluster). PM

499 and EP are supported by Biolaffort (Laffort ${ }^{\circledR}$ Research \& Development subsidiary) for this project, in

500 addition PM received a grant from Aquitaine Region (Sesam Project) for genome sequencing and

501 QTL analysis.

\section{Ethical approval}

503 This article does not contain any studies with human participants or animals performed by any of the 504 authors.

\section{Availability of data}

506 Raw data may be supplied upon request, at the discretion of the corresponding authors.

\section{Authors' contributions}

508 All authors contributed to the study conception and design. LB carried out laboratory fermentation

509 experiments; PM and EP provided yeast strains. Data analysis and interpretation was performed by

510 LB, EP and PM. LB wrote the manuscript and EP, JS, KS, JGM, VJ and PM reviewed and revised the

511 manuscript. All authors read and approved the final manuscript.

\section{Acknowledgements}

513 We thank Hélène Mesnage for her assistance in performing the QTL fermentation experiment. We

514 also acknowledge Nick van Holst Pellekaan for capturing images of the automated fermentation

515 platform.

\section{Conflicts of interest}

517 EP and PM are employed by Biolaffort. This does not alter the authors' adherence to all the journal 518 policies on sharing data and materials. 


\section{References}

524 Abrahamse CE, Bartowsky EJ (2012) Timing of malolactic fermentation inoculation in Shiraz grape

525 must and wine: influence on chemical composition. World J Microbiol Biotechnol 28: 255-265. doi:

526 10.1007/s11274-011-0814-3

527 Alexandre H, Costello PJ, Remize F, Guzzo J, Guilloux-Benatier M (2004) Saccharomyces

528 cerevisiae-Oenococcus oeni interactions in wine: current knowledge and perspectives. Int J Food

529 Microbiol 93:141-154. doi: 10.1016/j.ijfoodmicro.2003.10.013

530 Antalick G, Perello MC, de Revel G (2013) Co-inoculation with yeast and LAB under winery

531 conditions: modification of the aromatic profile of merlot wines. S Afr J Enol Vitic 34:223-232. doi:

$532 \quad 10.21548 / 34-2-1098$

533 Arnink K, Henick-Kling T (2005) Influence of Saccharomyces cerevisiae and Oenococcus oeni strains

534 on successful malolactic conversion in wine. Am J Enol Vitic 56:228-237.

535 Arroyo-López FN, Bautista-Gallego J, Domínguez-Manzano V, Romero-Gil F, Rodriguez-Gómez P, 536 García-García A, Garrido-Fernández R, Jiménez-Díaz (2012) Formation of lactic acid bacteria-yeasts communities on the olive surface during Spanish-style Manzanilla fermentations. Food Microbiol 32:295-301. doi: 10.1016/j.fm.2012.07.003

Atanassova M, Choiset Y, Dalgalarrondo M, Chobert JM, Dousset X, Ivanova I, Haertlé T (2003) Isolation and partial biochemical characterization of a proteinaceous anti-bacteria and anti-yeast compound produced by Lactobacillus paracasei subsp. paracasei strain M3. Int J Food Microbiol 87:63-73. doi: 10.1016/S0168-1605(03)00054-0

543 Bartle L, Sumby K, Sundstrom J, Jiranek V (2019) The microbial challenge of winemaking: yeast544 bacteria compatibility. FEMS Yeast Res 19:foz040. doi: 10.1093/femsyr/foz040

545 Bokulich NA, Bamforth CW (2013) The microbiology of malting and brewing. Microbiol Mol Biol Rev 546 77:157-172. doi: 10.1128/MMBR.00060-12

547 Brice C, Sanchez I, Bigey F, Legras JL, Blondin B (2014) A genetic approach of wine yeast

548 fermentation capacity in nitrogen-starvation reveals the key role of nitrogen signaling. BMC Genomics 549 15:495. doi: 10.1186/1471-2164-15-495

550 Broman KW, Wu H, Sen Ś, Churchill GA (2003) R/qtl: QTL mapping in experimental crosses.

551 Bioinformatics 19:889-890. doi: 10.1093/bioinformatics/btg112

552 Cañas PMI, Pérez-Martín F, Romero EG, Prieto SS, Herreros MDLLP (2012) Influence of inoculation 553 time of an autochthonous selected malolactic bacterium on volatile and sensory profile of Tempranillo 554 and Merlot wines. Int J Food Microbiol 156:245-254. doi: 10.1016/j.ijfoodmicro.2012.03.033

555 Cañas PMI, Romero EG, Pérez-Martín F, Seseña S, Palop ML (2015) Sequential inoculation versus 556 co-inoculation in Cabernet Franc wine fermentation. Food Sci Technol Int 21:203-212. doi. $557 \quad 10.1177 / 1082013214524585$

558 Capucho I, San Romão MV (1994) Effect of ethanol and fatty acids on malolactic activity of 559 Leuconostoc oenos. Appl Microbiol Biotechnol 42:391-395. doi: 10.1007/BF00902747

560 Carrete R, Vidal MT, Bordons A, Constantí M (2002) Inhibitory effect of sulfur dioxide and other stress 561 compounds in wine on the ATPase activity of Oenococcus oeni. FEMS Microbiol Lett 211:155-159. 562 doi: 10.1111/j.1574-6968.2002.tb11218.x

563 Chasseriaud L, Coulon J, Marullo P, Albertin W, Bely M (2018) New oenological practice to promote 564 non-Saccharomyces species of interest: Saturating grape juice with carbon dioxide. Appl Microbiol

565 Biotechnol 102:3779-3791. doi: 10.1007/s00253-018-8861-4 
566 Chen X, Niks RE, Hedley PE, Morris J, Druka A, Marcel TC, Vels A, Waugh R (2010) Differential gene 567 expression in nearly isogenic lines with QTL for partial resistance to Puccinia hordei in barley. BMC 568 Genomics 11:629. doi: 10.1186/1471-2164-11-629

569 Churchill GA, Doerge RW (1994) Empirical threshold values for quantitative trait mapping. Genetics 570 138:963-971.

571 Comitini F, Ciani M (2007) The inhibitory activity of wine yeast starters on malolactic bacteria. Ann 572 Microbiol 57:61-66. Doi: 10.1007/BF03175051

573 Comitini F, Ferretti R, Clementi F, Mannazzu I, Ciani M (2005) Interactions between Saccharomyces 574 cerevisiae and malolactic bacteria: preliminary characterization of a yeast proteinaceous compound 575 (s) active against Oenococcus oeni. J Appl Microbiol 99:105-111. doi: 10.1111/j.1365-

$576 \quad 2672.2005 .02579 . x$

577 Decroocq V, Foulongne M, Lambert P, Gall OL, Mantin C, Pascal T, Schurdi-Levraud V, Kervella J 578 (2005) Analogues of virus resistance genes map to QTLs for resistance to sharka disease in Prunus 579 davidiana. Mol Genet Genomics 272:680-689. doi: 10.1007/s00438-004-1099-0

580 Delcourt F, Taillandier P, Vidal F, Strehaiano P (1995) Influence of pH, malic acid and glucose 581 concentrations on malic acid consumption by Saccharomyces cerevisiae. Appl Microbiol Biotechnol 582 43:321-324. doi: 10.1007/BF00172832

583 Divol B, Du Toit M, Duckitt E (2012) Surviving in the presence of sulphur dioxide: Strategies 584 developed by wine yeasts. Appl Microbiol Biotechnol 95:601-613. doi: 10.1007/s00253-012-4186-x

585 Eder M, Sanchez I, Brice C, Camarasa C, Legras JL, Dequin S (2018) QTL mapping of volatile 586 compound production in Saccharomyces cerevisiae during alcoholic fermentation. BMC Genomics 587 19:166. doi: 10.1186/s12864-018-4562-8

588 El-Gendy SM, Abdel-Galil H, Shahin Y, Hegazi FZ (1983) Acetoin and diacetyl production by homo589 and heterofermentative lactic acid bacteria. J Food Protect 46:420-425. doi: 10.4315/0362-028X$590 \quad 46.5 .420$

591 Eun MH, Han JH, Yoon JB, Lee J (2016) QTL mapping of resistance to the Cucumber mosaic virus 592 P1 strain in pepper using a genotyping-by-sequencing analysis. Hortic Environ Biotechnol 57:589593 597. doi: 10.1007/s13580-016-0128-3

594 Furukawa S, Nojima N, Yoshida K, Hirayama S, Ogihara H, Morinaga Y (2011) The importance of 595 inter-species cell-cell co-aggregation between Lactobacillus plantarum ML11-11 and Saccharomyces 596 cerevisiae BY4741 in mixed-species biofilm formation. Biosci Biotechnol Biochem 75:1430-1434. doi: $597 \quad 10.1271 /$ bbb. 100817

598 Furukawa S, Yoshida K, Ogihara H, Yamasaki M, Morinaga Y (2010) Mixed-species biofilm formation 599 by direct cell-cell contact between brewing yeasts and lactic acid bacteria. Biosci Biotechnol Biochem. 600 74: 2316-2319. doi: 10.1271/bbb.100350

601 Gao C, Fleet GH (1995) Degradation of malic and tartaric acids by high density cell suspensions of 602 wine yeasts. Food Microbiol 12:65-71. doi: 10.1016/S0740-0020(95)80080-8

603 García-Ríos E, Guillamón JM (2019) Sulfur dioxide resistance in Saccharomyces cerevisiae: beyond 604 SSU1. Microb Cell 6:527-530. doi: 10.15698/ mic2019.12.699

605 García-Ríos E, Nuévalos M, Barrio E, Puig S, Guillamón JM (2019) A new chromosomal

606 rearrangement improves the adaptation of wine yeasts to sulfite. Environ Microbiol 21:1771-1781.

607 doi: $10.1111 / 1462-2920.14586$ 
608 Goto-Yamamoto N, Kitano K, Shiki K, Yoshida Y, Suzuki T, Iwata T, Yamane Y, Hara S (1998) SSU1-

$609 \mathrm{R}$, a sulfite resistance gene of wine yeast, is an allele of SSU1 with a different upstream sequence. J

610 Ferment Bioeng 86:427-433. doi: 10.1016/S0922-338X(98)80146-3

611 Guzzo J, Jobin MP, Delmas F, Fortier LC, Garmyn D, Tourdot-Maréchal R, Lee B, Diviès C (2000)

612 Regulation of stress response in Oenococcus oeni as a function of environmental changes and

613 growth phase. Int J Food Microbiol 55:27-31. doi: 10.1016/S0168-1605(00)00209-9

614 Haley CS, Knott SA (1992) A simple regression method for mapping quantitative trait loci in line

615 crosses using flanking markers. Heredity 69:315-324. Doi: 10.1038/hdy.1992.131

616 Hranilovic A, Gambetta JM, Schmidtke L, Boss PK, Grbin PR, Masneuf-Pomarede I, Bely M, Albertin

617 W, Jiranek V (2018) Oenological traits of Lachancea thermotolerans show signs of domestication and

618 allopatric differentiation. Sci Rep 8:1-13. doi: 10.1038/s41598-018-33105-7

619 Huang C, Roncoroni M, Gardner RC (2014) MET2 affects production of hydrogen sulfide during wine

620 fermentation. Appl Microbiol Biotechnol 98:7125-7135. doi: 10.1007/s00253-014-5789-1

621 Jara M, Cubillos FA, García V, Salinas F, Aguilera O, Liti G, Martínez C (2014) Mapping genetic

622 variants underlying differences in the central nitrogen metabolism in fermenter yeasts. PLoS One

623 9:e86533. doi: 10.1371/journal.pone.0086533

624 Jarosz DF, Brown JC, Walker GA, Datta MS, Ung WL, Lancaster AK, Rotem A, Chang A, Newby GA,

625 Weitz DA, Bisson LF (2014) Cross-kingdom chemical communication drives a heritable, mutually

626 beneficial prion-based transformation of metabolism. Cell 158:1083-1093. doi:

627 10.1016/j.cell.2014.07.025

628 Knoll C, Fritsch S, Schnell S, Grossmann M, Krieger-Weber S, Du Toit M, Rauhut D (2012) Impact of 629 different malolactic fermentation inoculation scenarios on Riesling wine aroma. World J Microbiol

630 Biotechnol 28:1143-1153. doi: 10.1007/s11274-011-0917-x

631 Liti G, Louis EJ (2012) Advances in quantitative trait analysis in yeast. PLoS Genet 8:e1002912. doi: 632 10.1371/journal.pgen.1002912

633 Liu SQ, Pilone GJ (2000) An overview of formation and roles of acetaldehyde in winemaking with 634 emphasis on microbiological implications. Int J Food Sci Technol 35: 49-61. doi:10.1046/j.1365-

$6352621.2000 .00341 . x$

636 Martí-Raga M, Peltier E, Mas A, Beltran G, Marullo P (2017) Genetic causes of phenotypic adaptation 637 to the second fermentation of sparkling wines in Saccharomyces cerevisiae. G3 Genes Genom Genet 638 7:399-412. doi: 10.1534/g3.116.037283

639 Marullo P, Aigle M, Bely M, Masneuf-Pomarede I, Durrens P, Dubourdieu D, Yvert G (2007b) Single

640 QTL mapping and nucleotide-level resolution of a physiologic trait in wine Saccharomyces cerevisiae 641 strains. FEMS Yeast Res 7:941-952. doi: 10.1111/j.1567-1364.2007.00252.x

642 Marullo P, Claisse O, Eder ML, Börlin M, Feghali N, Bernard M, Legras JL, Albertin W, Rosa AL, 643 Masneuf-Pomarede I (2020) SSU1 checkup, a rapid tool for detecting chromosomal rearrangements 644 related to the SSU1 promoter in Saccharomyces cerevisiae: an ecological and technological study on 645 wine yeast. Front Microbiol 11:1331. doi: 10.3389/fmicb.2020.01331

646 Marullo P, Durrens P, Peltier E, Bernard M, Mansour C, Dubourdieu D (2019) Natural allelic variations 647 of Saccharomyces cerevisiae impact stuck fermentation due to the combined effect of ethanol and 648 temperature; a QTL-mapping study. BMC Genomics 20:680. doi: 10.1186/s12864-019-5959-8

649 Marullo P, Yvert G, Bely M, Aigle M, Dubourdieu D (2007a) Efficient use of DNA molecular markers to 650 construct industrial yeast strains. FEMS Yeast Res 7:1295-1306. doi: 10.1111/j.1567-

$651 \quad 1364.2007 .00281 . x$ 
652 Mendoza LM, de Nadra MCM, Farías ME (2010) Antagonistic interaction between yeasts and lactic 653 acid bacteria of oenological relevance: Partial characterization of inhibitory compounds produced by 654 yeasts. Food Res Int 43:1990-1998. doi: 10.1016/j.foodres.2010.05.017

655 Mounier J, Monnet C, Vallaeys T, Arditi R, Sarthou AS, Hélias A, Irlinger F (2008) Microbial

656 interactions within a cheese microbial community. Appl Environ Microbiol 74:172-181. doi:

657 10.1128/AEM.01338-07

658 Muñoz V, Beccaria B, Abreo E (2014) Simultaneous and successive inoculations of yeasts and lactic 659 acid bacteria on the fermentation of an unsulfited Tannat grape must. Braz J Microbiol 45:59-66. doi: $66010.1590 /$ S1517-83822014000100009

661 Nehme N, Mathieu F, Taillandier P (2008) Quantitative study of interactions between Saccharomyces 662 cerevisiae and Oenococcus oeni strains. J Ind Microbiol Biotechnol 35:685-693. doi: 10.1007/s10295$663 \quad 008-0328-7$

664 Nehme N, Mathieu F, Taillandier P (2010) Impact of the co-culture of Saccharomyces cerevisiae665 Oenococcus oeni on malolactic fermentation and partial characterization of a yeast-derived inhibitory 666 peptidic fraction. Food Microbiol 27:150-157. doi: 10.1016/j.fm.2009.09.008

667 Nissen P, Nielsen D, Arneborg N (2003) Viable Saccharomyces cerevisiae cells at high

668 concentrations cause early growth arrest of non-Saccharomyces yeasts in mixed cultures by a cell669 cell contact-mediated mechanism. Yeast 20:331-341. doi: 10.1002/yea.965

670 Nissen P, Nielsen D, Arneborg N (2004) The relative glucose uptake abilities of non-Saccharomyces 671 yeasts play a role in their coexistence with Saccharomyces cerevisiae in mixed cultures. Appl 672 Microbiol Biotechnol 64:543-550. doi: 10.1007/s00253-003-1487-0

673 Osborne JP, Edwards CG (2006) Inhibition of malolactic fermentation by Saccharomyces during 674 alcoholic fermentation under low- and high-nitrogen conditions: a study in synthetic media. Aust J 675 Grape Wine Res 12:69-78. doi: 10.1111/j.1755-0238.2006.tb00045.x

676 Park H, Bakalinsky AT (2000) SSU1 mediates sulphite efflux in Saccharomyces cerevisiae. Yeast 677 16:881-888. doi: 10.1002/1097-0061(200007)16:10<881::AID-YEA576>3.0.CO;2-3

678 Peltier E, Bernard M, Trujillo M, Prodhomme D, Barbe JC, Gibon Y, Marullo P (2018a) Wine yeast 679 phenomics: A standardized fermentation method for assessing quantitative traits of Saccharomyces 680 cerevisiae strains in enological conditions. PLoS One 13:e0190094. doi: 681 10.1371/journal.pone.0190094

682 Peltier E, Friedrich A, Schacherer J, Marullo P (2019) Quantitative trait nucleotides impacting the 683 technological performances of industrial Saccharomyces cerevisiae strains. Front Genetics 10:683. 684 doi: $10.3389 /$ fgene.2019.00683

685 Peltier E, Sharma V, Raga MM, Roncoroni M, Bernard M, Jiranek V, Gibon Y, Marullo P (2018b) 686 Dissection of the molecular bases of genotype $x$ environment interactions: a study of phenotypic 687 plasticity of Saccharomyces cerevisiae in grape juices. BMC Genomics 19:772. doi: 10.1186/s12864$688 \quad 018-5145-4$

689 Pérez-Ortín JE, Querol A, Puig S, Barrio E (2002) Molecular characterization of a chromosomal 690 rearrangement involved in the adaptive evolution of yeast strains. Genome Res 12:1533-1539. doi: $691 \quad 10.1101 / \mathrm{gr} .436602$

692 R Core Team (2017) R: A language and environment for statistical computing. R Foundation for 693 Statistical Computing. https://www.R-project.org/. Accessed 4 September 2017

694 Rankine BC, Pocock KF (1970) Alkalimetric determination of sulphur dioxide in wine. Aust Wine Brew 695 Spirit Rev 88:40-44. 
696 Renault P, Coulon J, de Revel G, Barbe JC, Bely M (2015) Increase of fruity aroma during mixed T.

697 delbrueckii/S. cerevisiae wine fermentation is linked to specific esters enhancement. Int J Food

698 Microbiol 207:40-48. doi: 10.1016/j.ijfoodmicro.2015.04.037

699 Renault P, Coulon J, Moine V, Thibon C, Bely M (2016) Enhanced 3-sulfanylhexan-1-ol production in 700 sequential mixed fermentation with Torulaspora delbrueckii/Saccharomyces cerevisiae reveals a 701 situation of synergistic interaction between two industrial strains. Front Microbiol 7:293. doi:

$702 \quad 10.3389 /$ fmicb.2016.00293

703 Renault P, Miot-Sertier C, Marullo P, Hernández-Orte P, Lagarrigue L, Lonvaud-Funel A, Bely M

704 (2009) Genetic characterization and phenotypic variability in Torulaspora delbrueckii species:

705 potential applications in the wine industry. Int J Food Microbiol 134:201-210. doi:

706 10.1016/j.ijfoodmicro.2009.06.008

707 Renault PE, Albertin W, Bely M (2013) An innovative tool reveals interaction mechanisms among

708 yeast populations under oenological conditions. Appl Microbiol Biotechnol 97:4105-4119. doi:

709 10.1007/s00253-012-4660-5

710 Renouf V, Claisse O, Lonvaud-Funel A (2007) Inventory and monitoring of wine microbial consortia.

711 Appl Microbiol Biotechnol 75:149-164. doi: 10.1007/s00253-006-0798-3

712 Ribéreau-Gayon P, Dubourdieu D, Donèche B, Lonvaud A (2006) Handbook of enology, Vol. 1: The

713 microbiology of wine and vinifications, 2nd edn. Wiley, doi:10.1002/0470010363

714 Roncoroni M (2014) Quantitative trait loci mapping in winemaking yeast. Dissertation, University of

715 Auckland

716 Roncoroni M, Santiago M, Hooks DO, Moroney S, Harsch MJ, Lee SA, Richards KD, Nicolau L,

717 Gardner RC (2011) The yeast IRC7 gene encodes a $\beta$-lyase responsible for production of the varietal

718 thiol 4-mercapto-4-methylpentan-2-one in wine. Food Microbiol 28:926-935. doi:

$719 \quad 10.1016 / j . f m .2011 .01 .002$

720 Rossouw D, Du Toit M, Bauer FF (2012) The impact of co-inoculation with Oenococcus oeni on the

721 trancriptome of Saccharomyces cerevisiae and on the flavour-active metabolite profiles during

722 fermentation in synthetic must. Food Microbiol 29:121-131. doi: 10.1016/j.fm.2011.09.006

723 Sadoudi M, Tourdot-Maréchal R, Rousseaux S, Steyer D, Gallardo-Chacón JJ, Ballester J, Vichi S,

724 Guérin-Schneider R, Caixach J, Alexandre H (2012) Yeast-yeast interactions revealed by aromatic

725 profile analysis of Sauvignon Blanc wine fermented by single or co-culture of non-Saccharomyces

726 and Saccharomyces yeasts. Food Microbiol 32:243-253. doi: 10.1016/j.fm.2012.06.006

727 Salinas F, Cubillos FA, Soto D, Garcia V, Bergström A, Warringer J, Ganga MA, Louis EJ, Liti G,

728 Martinez C (2012) The genetic basis of natural variation in oenological traits in Saccharomyces

729 cerevisiae. PloS One 7:e49640. doi: 10.1371/journal.pone.0049640

730 Steinmetz LM, Scharfe C, Deutschbauer AM, Mokranjac D, Herman ZS, Jones T, Chu AM, Giaever 731 G, Prokisch H, Oefner PJ, Davis RW (2002b) Systematic screen for human disease genes in yeast. 732 Nat Genet 31:400-404. doi: 10.1038/ng929

733 Steinmetz LM, Sinha H, Richards DR, Spiegelman JI, Oefner PJ, McCusker JH, Davis RW (2002a)

734 Dissecting the architecture of a quantitative trait locus in yeast. Nature 416:326-330. doi:

$73510.1038 / 416326 a$

736 Steyer D, Ambroset C, Brion C, Claudel P, Delobel P, Sanchez I, Erny C, Blondin B, Karst F, Legras

$737 \mathrm{JL}$ (2012) QTL mapping of the production of wine aroma compounds by yeast. BMC Genomics

738 13:573. doi: 10.1186/1471-2164-13-573 
739 Tempère S, Marchal A, Barbe JC, Bely M, Masneuf-Pomarede I, Marullo P, Albertin W (2018) The

740 complexity of wine: clarifying the role of microorganisms. Appl Microbiol Biotechnol 102:3995-4007.

741 doi: 10.1007/s00253-018-8914-8

742 Treu L, Toniolo C, Nadai C, Sardu A, Giacomini A, Corich V, Campanaro S (2014) The impact of

743 genomic variability on gene expression in environmental Saccharomyces cerevisiae strains. Environ

744 Microbiol 16:1378-1397. doi: 10.1111/1462-2920.12327

745 Tristezza M, di Feo L, Tufariello M, Grieco F, Capozzi V, Spano G, Mita G (2016) Simultaneous

746 inoculation of yeasts and lactic acid bacteria: Effects on fermentation dynamics and chemical

747 composition of Negroamaro wine. LWT-Food Sci Technol 66:406-412. doi: 10.1016/j.Iwt.2015.10.064

748 Walker ME, Nguyen TD, Liccioli T, Schmid F, Kalatzis N, Sundstrom JF, Gardner JM Jiranek V (2014)

749 Genome-wide identification of the Fermentome; genes required for successful and timely completion

750 of wine-like fermentation by Saccharomyces cerevisiae. BMC Genomics 15:552. doi: 10.1186/1471-

$751 \quad 2164-15-552$

752 Weng J, Gu S, Wan X, Gao H, Guo T, Su N, Lei C, Zhang X, Cheng Z, Guo X, Wang J (2008)

753 Isolation and initial characterization of GW5, a major QTL associated with rice grain width and weight.

754 Cell Res 18:1199-1209. doi: 10.1038/cr.2008.307

755 Yéramian N, Chaya C, Suárez Lepe JA (2007) L-(-)-malic acid production by Saccharomyces spp.

756 during the alcoholic fermentation of wine. J Agric Food Chem 55:912-919. doi: 10.1021/jf061990w

757 Zimmer A, Durand C, Loira N, Durrens P, Sherman DJ, Marullo P (2014) QTL dissection of lag phase 758 in wine fermentation reveals a new translocation responsible for Saccharomyces cerevisiae

759 adaptation to sulfite. PLoS One 9:e86298. doi: 10.1371/journal.pone.0086298 
761 Table 1: Yeast strains used in this study

\begin{tabular}{|c|c|c|c|c|}
\hline Strain & Comment & Genotype & Origin & $\begin{array}{l}\text { Culture collection } \\
\text { WDCM-791 (CRB } \\
\text { ISVV, Bordeaux) }\end{array}$ \\
\hline SB & $\begin{array}{l}\text { Monosporic clone of } \\
\text { Actiflore } \AA^{8} \mathrm{BO} 213 \\
\text { (Laffort } \AA \text {, Bordeaux, } \\
\text { France) }\end{array}$ & $\mathrm{HO} / \mathrm{HO}$, diploid & $\begin{array}{l}\text { Peltier et al. } \\
\text { (2018b) }\end{array}$ & CRBO L2001 \\
\hline GN & $\begin{array}{l}\text { Monosporic clone of } \\
\text { Zymaflore }{ }^{\circledR} \text { VL1 } \\
\text { (Laffort }{ }^{\circledR}, \text { Bordeaux, } \\
\text { France) }\end{array}$ & $\mathrm{HO} / \mathrm{HO}$, diploid & $\begin{array}{l}\text { Peltier et al. } \\
\text { (2018b) }\end{array}$ & CRBO L2002 \\
\hline SBxGN & F1 hybrid SBxGN & $\mathrm{HO} / \mathrm{HO}$, diploid & $\begin{array}{l}\text { Peltier et al. } \\
(2018 b)\end{array}$ & CRBO L2003 \\
\hline $\mathrm{BN}$ & F1 hybrid hoSBxGN & HO/ ho::kanMx4, diploid & $\begin{array}{l}\text { Marullo et } \\
\text { al. (2007b) }\end{array}$ & CRBO L2004 \\
\hline pop BN & $\begin{array}{l}67 \text { progeny clones of } \\
\text { BN (hoSBxGN). } \\
\text { Labelled with prefix } \\
\text { "CM" followed by an } \\
\text { ID number }\end{array}$ & ho::kanMx4, haploids & $\begin{array}{l}\text { Marullo et } \\
\text { al. (2007b) }\end{array}$ & \\
\hline $\mathrm{S} \Delta \mathrm{G} 092$ & $\begin{array}{l}\text { Hemizygous hybrid } \\
\text { isogenic to SBxGN }\end{array}$ & $\begin{array}{l}\text { ho/ho, YPL092 } \\
\text { YPLO92 }^{\mathrm{SB}} \text { : diploid }\end{array}$ & $\begin{array}{l}\text { Zimmer et } \\
\text { al. (2014) }\end{array}$ & CRBO L2006 \\
\hline $\mathrm{G} \Delta \mathrm{S} 092$ & $\begin{array}{l}\text { Hemizygous hybrid } \\
\text { isogenic to SBxGN }\end{array}$ & 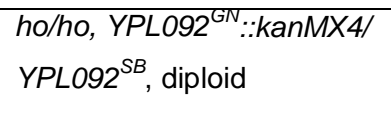 & $\begin{array}{l}\text { Zimmer et } \\
\text { al. (2014) }\end{array}$ & CRBO L2007 \\
\hline
\end{tabular}

762 
763 Table 2: AF and MLF measures used to perform QTL mapping, BN progeny evaluation or statistical

764 analysis for comparison of hemizygous strains with their corresponding SBxGN hybrids.

765 Abbreviations, if assigned, are shown below:

\begin{tabular}{|c|c|c|c|}
\hline AF measures & Abbreviation & MLF measures & Abbreviation \\
\hline $\begin{array}{l}\text { Time to complete } \\
\text { AF (hours) }\end{array}$ & tend-AF & $\begin{array}{l}\text { Residual L-malic acid } \\
\text { concentration for } \\
\text { yeast alone } \\
\text { fermentations } \\
\left(\mathrm{g} \mathrm{L}^{-1}\right)\end{array}$ & Not assigned \\
\hline $\begin{array}{l}\text { Time to reach } \\
\text { equivalent of } 35 \% \\
\mathrm{CO}_{2} \text { (175.53 } \mathrm{g} \mathrm{L}^{-1} \\
\text { total sugar) }\end{array}$ & t35-AF & $\begin{array}{l}\text { Percentage L-malic } \\
\text { acid consumption for } \\
\text { yeast-LAB } \\
\text { co-inoculation } \\
\text { fermentations }\end{array}$ & Pct_malic_co \\
\hline $\begin{array}{l}\text { Time to reach } \\
\text { equivalent of } 50 \% \\
\mathrm{CO}_{2}\left(143.62 \mathrm{~g} \mathrm{~L}^{-1}\right. \\
\text { total sugar) }\end{array}$ & t50-AF & $\begin{array}{l}\text { Estimated overall } \\
\text { L-malic acid } \\
\text { consumed by LAB (g } \\
\left.\mathrm{L}^{-1}\right)\end{array}$ & Malic_acid_LAB_consumed \\
\hline $\begin{array}{l}\text { Time to reach } \\
\text { equivalent of } 80 \% \\
\mathrm{CO}_{2}\left(79.79 \mathrm{~g} \mathrm{~L}^{-1}\right. \\
\text { total sugar) }\end{array}$ & t80-AF & $\begin{array}{l}\text { Time to complete } \\
\text { MLF (hours) }\end{array}$ & tend-MLF \\
\hline $\begin{array}{l}\text { Slope between t50- } \\
\text { AF and t80-AF }\end{array}$ & s50-80-AF & & \\
\hline $\begin{array}{l}\text { Percentage L-malic } \\
\text { acid consumption } \\
\text { or production by } \\
\text { yeast alone }\end{array}$ & Pct_malic_AF & & \\
\hline
\end{tabular}

